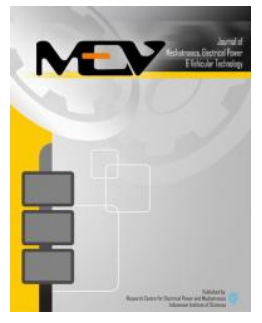

Mechatronics, Electrical Power, and Vehicular Technology

\title{
COMPARISON OF UNMODULATED CURRENT CONTROL Characteristics of Permanent Magnet SYNCHRONOUS MOTOR
}

\author{
Anwar Muqorobin ${ }^{\mathrm{a}, *}$, Pudji Irasari $^{\mathrm{a}}$, Taufik $^{\mathrm{b}}$ \\ ${ }^{a}$ Research Centre for Electrical Power and Mechatronics, Indonesian Institute of Sciences \\ Jl. Sangkuriang Komplek LIPI Gedung 20 Lantai 2 Bandung, 40135, Indonesia \\ ${ }^{\mathrm{b}}$ Electric Power Institute, California Polytechnic State University \\ San Luis Obispo, CA 93407, United States of America
}

Received 10 September 2014; received in revised form 29 October 2014; accepted 29 October 2014 Published online 24 December 2014

\begin{abstract}
This paper discusses comparison of unmodulated current controls in permanent magnet synchronous motor (PMSM), more specifically, on-off, sliding mode, predictive and hybrid controls. The purpose of this study is to select the most appropriate control technique to be adopted. The comparison method is preceded by modeling the motor and entering the values of the motor parameters. PI control is used for speed control and zero d-axis current is employed. Furthermore, performing simulation for each type of the selected current controls and analyzing their responses in terms of dq and abc currents, q-axis current response with step reference, as well as total harmonic distortion (THD). Simulation results show that the on-off control gives the best overall performance based on its abc-axis current ripple and THD at large load torque. The hybrid control shows the best response occurring only at the fastest transient time of q-axis current but its response exhibits bad qualities compared with other controls. The predictive control yields the best responses offering the smallest d-axis ripple current and THD at small load torque condition. The sliding mode control, however, does not exhibit any prominent performance compared to the others. Results presented in this paper further indicate that for the PMSM used in the simulation the most appropriate control is the predictive control.
\end{abstract}

Keywords: unmodulated current controls, on-off control, sliding mode control, predictive control and hybrid control.

\section{INTRODUCTION}

Permanent magnet synchronous motor (PMSM) has gradually shifted the use of induction motor for small to medium power applications. Compared to induction motor, PMSM has higher torque to current ratio, higher power to volume ratio as well as higher efficiency and power factor. In addition, without the existence of slip this type of motor is easier to control. Vector control that has been employed successfully for induction motor can simply be applied for PMSM.

In motor control, the most influencing parameter is torque that is proportional to the motor speed. Therefore, in a closed loop speed control, the control will provide torque reference associated with the desired speed. Meanwhile, load torque that has opposite correlation with system torque is considered as disturbance. To

* Corresponding Author. Phone: +62-22-2504770

E-mail: anwa006@lipi.go.id obtain a certain value of torque according to the reference given by the speed control, a torque control inside the closed loop speed control is engaged. An example is the direct torque control (DTC) which was initially applied for induction motor [1] and then was successfully introduced to PMSM [2, 3].

Since theoretically motor torque is proportional to current; hence, controlling current in vector control method is basically to control the motor torque. Some current controllers that have been implemented for PMSM are conventional nonlinear control (on-off, hysteresis, delta modulation) [4-6], PI control [79], internal model control [10, 11], linear matrix inequality [12], resonant control [13], sliding mode control [14-16], predictive control [17-22], hybrid control [23], and intelligence control [24, 25]. Furthermore, these controls can be categorized basically in two types: with modulation [7-15, 17-20, 22, 24, 25] and without modulation $[4-6,16,19,21,23]$. The modulated 


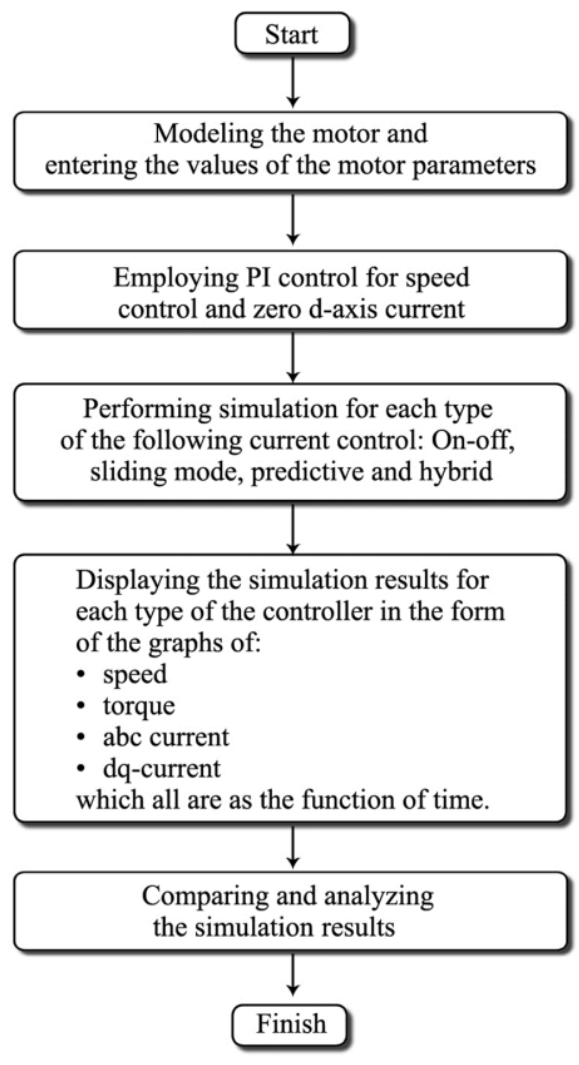

Figure 1. Flow chart for characteristic comparison of the current controls

control requires a process to calculate the duty cycle of pulse width modulation. On the other hand, the unmodulated control does not need such process since the control provides on and off actions directly into the switching components of inverter. Additionally, the modulated control has a better steady state response since its switching frequency is not varied. According to $[23,25,26]$, PI control with PWM gives better steady state response while the modern control has better response during transient condition. However, [21] demonstrates that PI control with PWM could provide better response in steady state and transient conditions.

This paper compares four unmodulated current control techniques for a PMSM including on-off control, sliding mode control, predictive control and hybrid control. Prior to this comparison study, the PMSM was manufactured and measurement of its parameters had been carried out [27]. The objective of this paper is to select the most appropriate control technique to be adopted.

\section{Methodology}

Comparison method of the characteristic of selected current controls is described using the flow chart in Figure 1. A block diagram of speed control for PMSM is illustrated in Figure 2. The speed control sets the reference of q-axis current. Below nominal speed, there are some strategies for $d$-axis current reference, those are zero $d$-axis current, maximum torque per ampere (MTPA), maximum efficiency, unity power factor and constant mutual flux linkage (CMFL) [28]. In this study, PI control is used for speed control and zero d-axis current is employed due to its simplicity and our investigation is focused on current control. PMSM is modeled in dq-axis with the following equations:

$$
\begin{aligned}
& v_{d}=R_{s} i_{d}+L_{d} \frac{\partial i_{d}}{\partial t}-\omega_{e} L_{q} i_{q} \\
& v_{q}=R_{s} i_{q}+L_{q} \frac{\partial i_{q}}{\partial t}+\omega_{e}\left(L_{d} i_{d}+\psi_{m}\right) \\
& T_{e m}=p \frac{3}{2}\left(\psi_{m} i_{q}+\left(L_{d}-L_{q}\right) i_{d} i_{q}\right) \\
& J \frac{\partial \omega_{m}}{\partial t}=T_{e m}-T_{L} \\
& \omega_{m}=\frac{\omega_{e}}{p}
\end{aligned}
$$

where $v_{d}, v_{q}$ represent $\mathrm{d}$ - and $\mathrm{q}$-axis stator voltage, $i_{d}$ and $i_{q}$ represent $\mathrm{d}$ - and q-axis stator current, $R_{s}$ is Stator resistance per phase, $L_{d}$ and $L_{q}$ represent $\mathrm{d}$ - and q-axis inductance, $T_{e m}$ is electromagnetic torque, $T_{L}$ is load torque, $J$ is motor and load moment of inertia, $p$ is the number of pole pair, $\omega_{e}$ is electrical angular velocity, $\omega_{m}$ is mechanical angular velocity, and $\psi_{m}$ is permanent magnet flux.

The d- and q-axis currents and voltages are obtained by using equation of abc to dq-axis transformation:

$$
\frac{2}{3}\left[\begin{array}{ccc}
\cos \theta & \cos \left(\theta-\frac{2 \pi}{3}\right) & \cos \left(\theta+\frac{2 \pi}{3}\right) \\
-\sin \theta & -\sin \left(\theta-\frac{2 \pi}{3}\right) & -\sin \left(\theta+\frac{2 \pi}{3}\right) \\
1 / 2 & 1 / 2 & 1 / 2
\end{array}\right] \text { (6) }
$$

while the inverse transformation from dq-axis to abc is

$$
\left[\begin{array}{ccc}
\cos \theta & -\sin \theta & 1 \\
\cos \left(\theta-\frac{2 \pi}{3}\right) & -\sin \left(\theta-\frac{2 \pi}{3}\right) & 1 \\
\cos \left(\theta+\frac{2 \pi}{3}\right) & -\sin \left(\theta+\frac{2 \pi}{3}\right) & 1
\end{array}\right]
$$

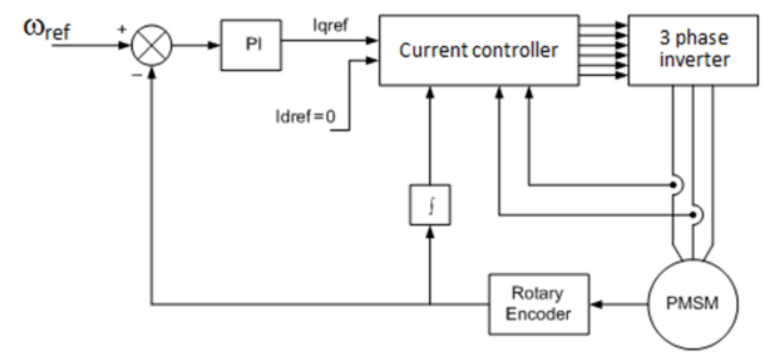

Figure 2. Block diagram of PMSM speed control [28] 


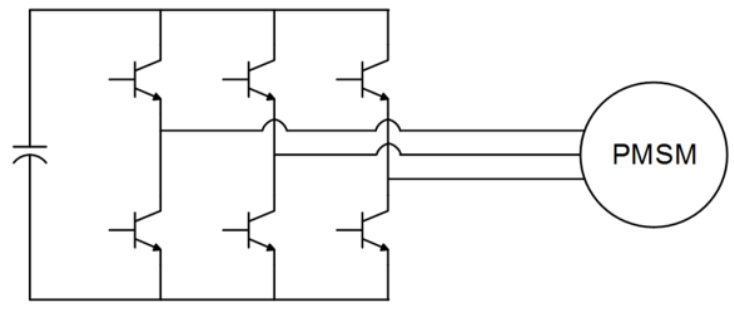

Figure 3. Three phase inverter topology for PMSM drive

The three phase inverter topology used to drive the PMSM and the voltage space vectors are shown in Figures 3 and 4 respectively. There are eight control combinations for switching the inverter (Table 1) [28]. The value of 1 means the upper switch is on and the lower one is off, while the value of 0 turns off the upper switch and on the lower one.

\section{A. On-off Control}

The on-off control for current control in PMSM is shown in Figure 5 [29]. This control has two actions of control (i.e. on and off) and it is referred to the unmodulated control where current references are set on abc axis [28]. Therefore, the current references from the speed control should be first converted to abc axis.

\section{B. Sliding Mode Control}

Sliding mode control uses sliding surface to determine the control action. The sliding surface used is [14]:

$$
s(t)=K_{p} e(t)+K_{i} \int e(t) d t
$$

Equation (8) is a PI control algorithm. The block diagram of current control on abc axis by using sliding mode is illustrated in Figure 6 [14]. The selection of abc coordinates on sliding mode control follows the same reason as that on the onoff control.

\section{Hybrid Control}

To design the hybrid control for a plant with dynamic model below

$$
\frac{\partial x(t)}{\partial t}=f(x)
$$

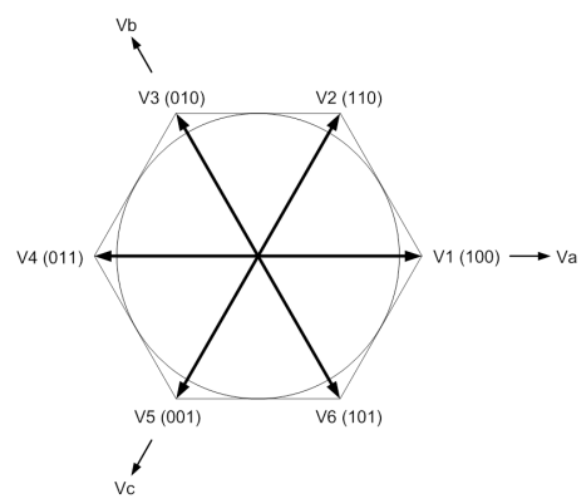

Figure 4. Voltage space vector of three phase inverter

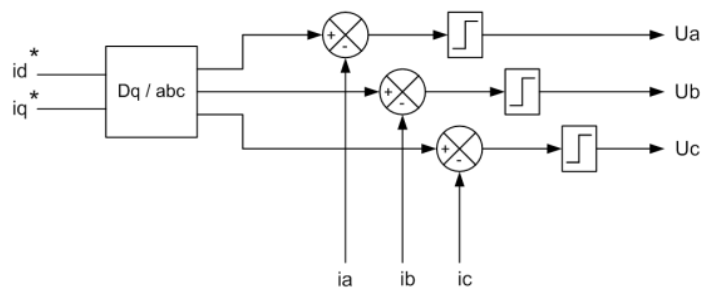

Figure 5. On-off control [29]

the following Lyapunov function is applied:

$$
V(x, t)=\frac{1}{2} e(t)^{2}
$$

with,

$$
e(t)=x(t)-x^{*}(t)
$$

To maintain the system stability, the condition that should be fulfilled is

$$
\frac{d V}{d t} \leq 0 \equiv \frac{\partial V}{\partial x}(x) f(x) \leq 0
$$

Or in this case the following should hold:

$$
e(t) f(x) \leq 0
$$

Eq.(1) and (2) can be rewritten as

$$
\begin{aligned}
& \frac{\partial i_{d}}{\partial t}=\frac{1}{L_{d}}\left(-R_{s} i_{d}+\omega_{e} L_{q} i_{q}+v_{d}\right) \\
& \frac{\partial i_{q}}{\partial t}=\frac{1}{L_{q}}\left(-R_{s} i_{q}-\omega_{e}\left(L_{d} i_{d}+\psi_{m}\right)+v_{q}\right)
\end{aligned}
$$

Elaboration of Eq.(13) yields,

$$
\left(i_{d}-i_{d}^{*}\right) \frac{\partial i_{d}}{\partial t}+\left(i_{q}-i_{q}^{*}\right) \frac{\partial i_{q}}{\partial t} \leq 0
$$

The eight combinations of the control are then transformed into dq-axis and substituted in equation (14) and (15). The selected control is the

Table 1.

Switching combinations of three phase inverter

\begin{tabular}{ll}
\hline Vector & $\begin{array}{l}\text { Combination of } \\
\text { Va, Vb, and Ve }\end{array}$ \\
\hline V0 & 000 \\
\hline V1 & 100 \\
\hline V2 & 110 \\
\hline V3 & 010 \\
\hline V4 & 011 \\
\hline V5 & 001 \\
\hline V6 & 101 \\
\hline V7 & 111 \\
\hline
\end{tabular}

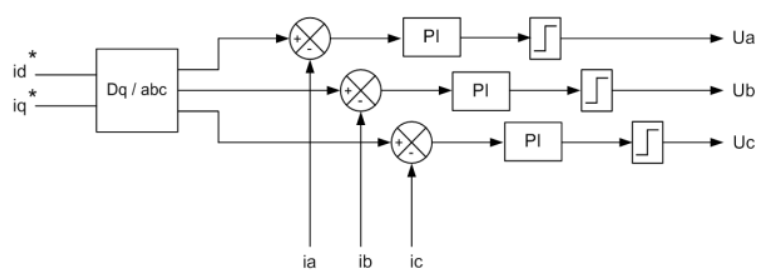

Figure 6. Sliding mode control [14] 


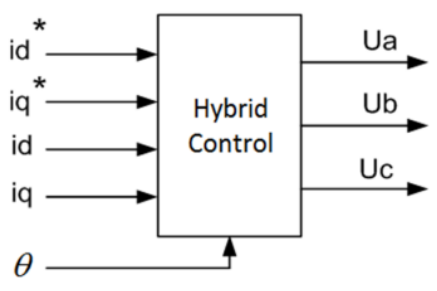

Figure 7. Hybrid control [28]

one giving the smallest value in equation (16) [23]. The block diagram of the hybrid control is shown in Figure 7 [28].

\section{Predictive Control}

Like hybrid control, predictive control also applies eight control combinations [29]. Integration of equation (14) and (15) is solved to obtain $i_{\mathrm{d}}$ and $i_{\mathrm{q}}$ currents to minimize the following function [19],

$$
g(t)=\left(i_{d}-i_{d}^{*}\right)^{2}+\left(i_{q}-i_{q}^{*}\right)^{2}
$$

\section{E. Motor Parameters}

The methods of measurement and calculation of the motor parameters have been presented in [27] and the results are listed in Table 2.

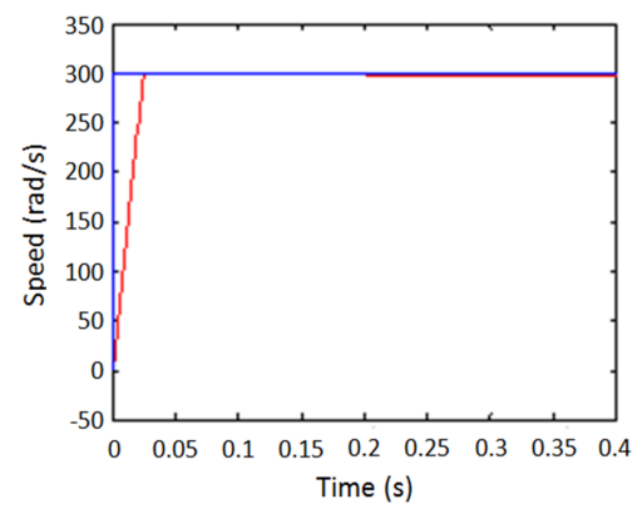

(a)

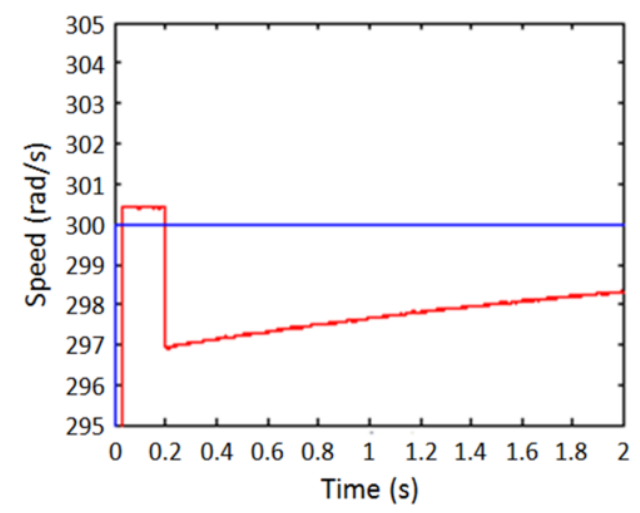

(b)

Figure 8. Motor speed characteristics, (a) Time to reach steady state, (b) Tendency to gain the reference point

\section{RESULTS AND DISCUSSION}

The four controllers are simulated with the same sampling time (1 $\mathrm{e}^{-5}$ second) and mechanical angular velocity reference of $300 \mathrm{rad} / \mathrm{s}$. The simulation is done first by loading the motor with the torque of $5 \mathrm{Nm}$ and then changed to $35 \mathrm{Nm}$ in 0.2 second. Meanwhile, the speed control employs PI control with $\mathrm{Kp}$ of 30 and $\mathrm{Ti}$ of 3 seconds. The simulation results are depicted in Figures 8 to 13 . The blue line is the reference signal and the red line is the controlled output signal.

Figure 8 describes the mechanical speed of the motor implementing on-off control. Within 0.2 seconds of the given torque, the motor can reach steady state in 0.05 seconds (Figure 8a). Despite the existence of offset error at steady state, the motor control tends to gain the reference point (Figure 8b). Figure 9 shows that in the steady state the motor torque follow the load torque closely. Controlling current by using the other control methods yields similar speed response to that of the on-off control.

The q-axis currents of the four controllers produce different transient responses as shown in Figure 10. From all controls, the predictive control is the only one that does not show the offset error. Meanwhile the ripple current

Table 2.

PMSM parameters

\begin{tabular}{ll}
\hline Parameters & Magnitude \\
\hline$P$ & $25 \mathrm{HP}$ \\
\hline$V$ & $62.5 \mathrm{~V}$ \\
\hline$p$ & 3 pole pairs \\
\hline$R_{\mathrm{s}}$ & $11.15 \mathrm{~m} \Omega$ \\
\hline$\psi_{\mathrm{m}}$ & 0.0639 weber \\
\hline$L_{\mathrm{d}}$ & $0.123 \mathrm{mH}$ \\
\hline$L_{\mathrm{q}}$ & $0.142 \mathrm{mH}$ \\
\hline $\mathrm{J}$ & $0.004177 \mathrm{~kg} \cdot \mathrm{m}^{2}$ \\
\hline
\end{tabular}

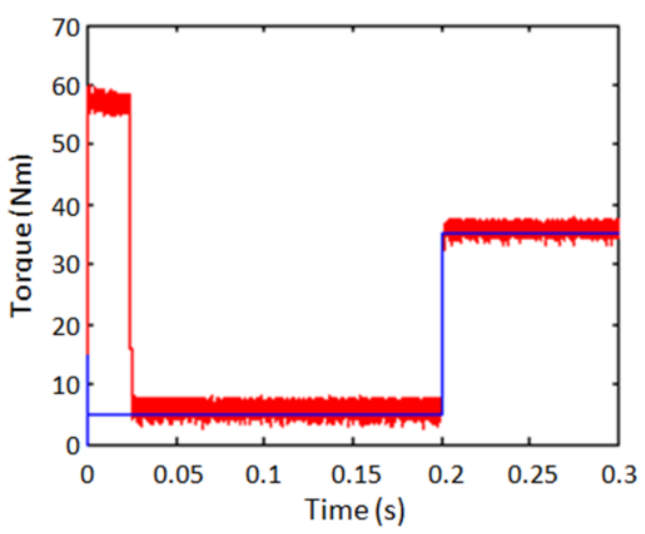

Figure 9. Motor torque 
characteristics of the predictive and hybrid controls reveal uniform frequency, although their amplitudes are higher than that of the on-off and sliding mode controls. Figure 11 illustrates the simulation of the transient response when the step reference is applied.

The results are summarized in Table 3 which shows that hybrid control yields the fastest

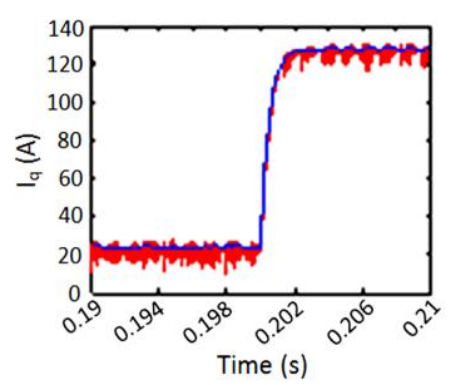

(a)

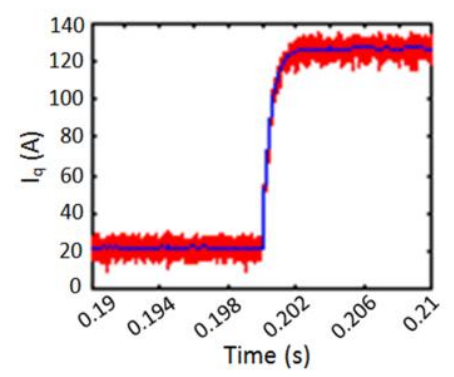

(c) transient time while the predictive control is the slowest. The replenishment of PI control in the on-off control (turns to sliding mode) does not improve the response of the system at steady state. Both on-off and sliding mode controls generate an average of q-axis current lower than the reference or what so called the offset error. Sliding mode control does not seem to reduce the

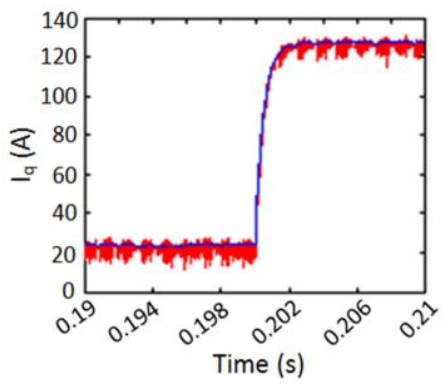

(b)

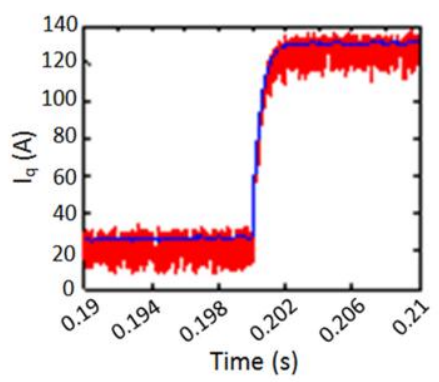

(d)

Figure 10. q-axis currents (a) On-off control (b) Sliding mode control (c) Predictive control (d) Hybrid control

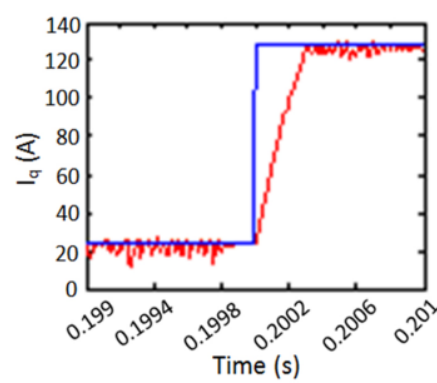

(a)

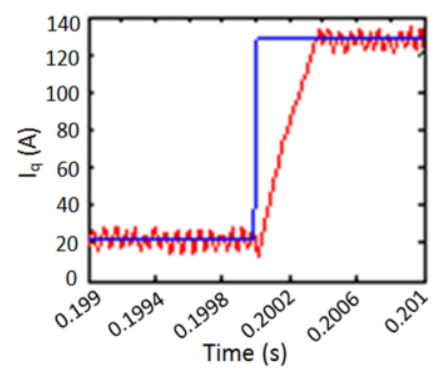

(c)

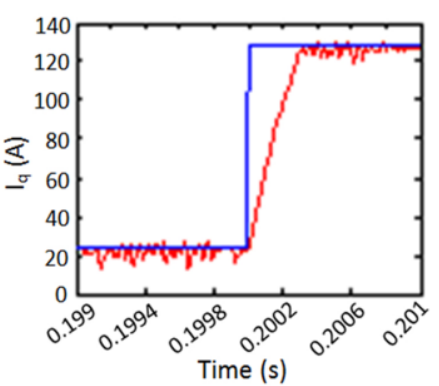

(b)

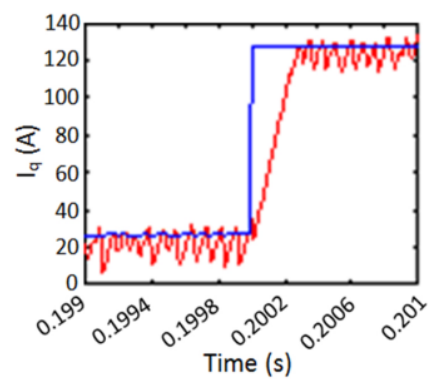

(d)

Figure 11. q-axis currents with step reference (a) On-off control (b) Sliding mode control (c) Predictive control (d) Hybrid control 
ripple produced by on-off control since both make use of the same final action that is without modulation.

Currents in the d-axis of the four controls are shown in Figure 12. It appears that the on-off control and sliding mode control give large d-axis ripple currents, followed by the hybrid control

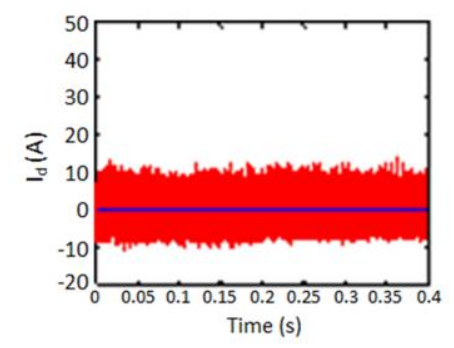

(a)

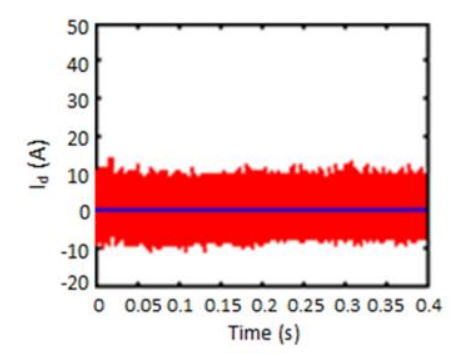

(c) and predictive control the smallest. The abc-axis currents of the four controls are exhibited in Figure 13. Paying attention to the peak of the sinusoidal wave, the ripple current produced by each controller in the order from the smallest to the largest are by the on-off control, sliding mode control, predictive control and hybrid control.

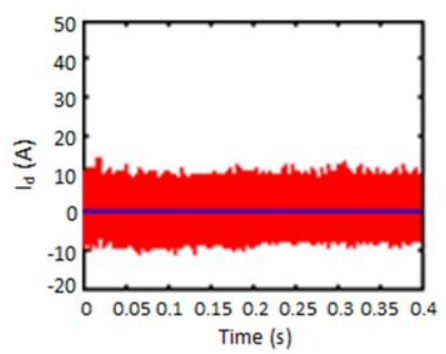

(b)

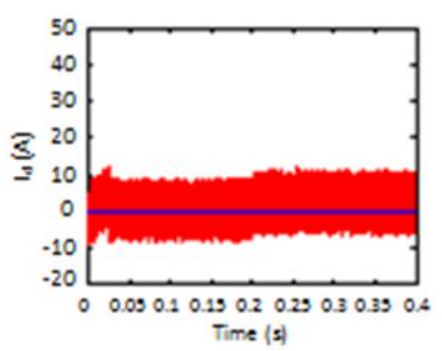

(d)

Figure 12. d-axis current (a) On-off control (b) Sliding mode control (c) Predictive control (d) Hybrid control

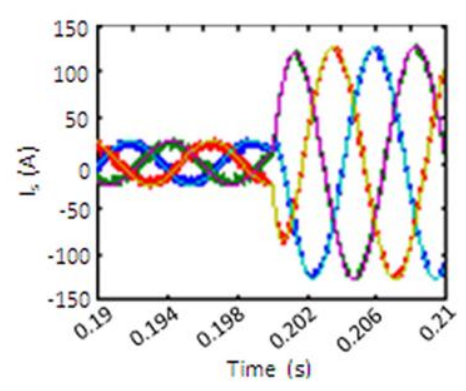

(a)

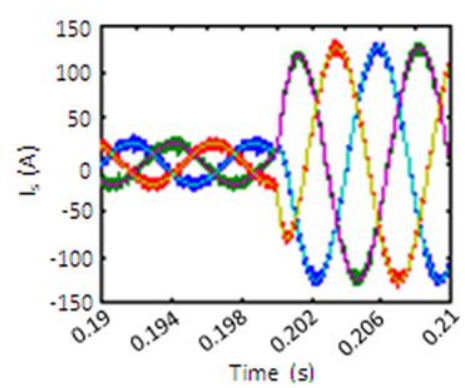

(c)

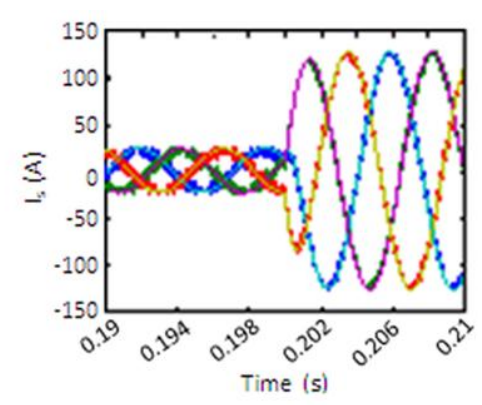

(b)

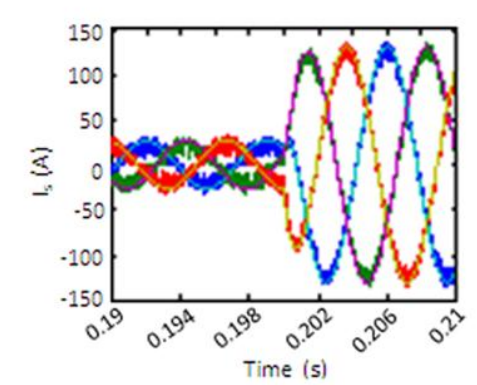

(d)

Figure 13. q-axis currents (a) On-off control (b) sliding mode control (c) Predictive control (d) Hybrid control 
Table 4.

THD at 35 N.m of the load torque

\begin{tabular}{ll}
\hline Control & THD \\
\hline On-off & $3.79 \%$ \\
\hline Sliding mode & $3.83 \%$ \\
\hline Predictive & $3.87 \%$ \\
\hline Hybrid & $5.36 \%$ \\
\hline
\end{tabular}

Tables 4 and 5 respectively represent THD of the motor when it is started with $35 \mathrm{Nm}$ and $5 \mathrm{Nm}$ of the load torque. From the two tables, it can be seen that the smallest harmonics is attained by two controllers at two opposite conditions, those are at low torque by the predictive control and at large torque by the on-off control. Meanwhile the hybrid controls always generate high harmonics at both conditions.

\section{Conclusion}

Comparative study of the four unmodulated current controls, namely on-off control, sliding mode control, predictive control and hybrid control, has been performed. Computer simulations were conducted to investigate the responses from each controller on their dq-axis and abc currents, transient response, q-axis current response with step reference, as well as THD at small and large load torques. The simulation results show different characteristics of each controller that can be concluded as follows:

- Good characteristic of the hybrid control is observed at the transient response of q-axis current $(290 \mu \mathrm{s})$ while other conditions yields bad quality of responses.

- The predictive control exhibits poor performance at the transient response of qaxis current $(380 \mu \mathrm{s})$. Its best responses are represented by the smallest of both d-axis ripple current and THD at $5 \mathrm{Nm}$ of load torque. With other test conditions, its performance is good as indicated by its q-axis ripple current responses without offset error at steady state.

- The on-off control produces is superior in both abc-axis ripple currents and THD at 35 Nm. However, its good performances are hindered by the existence of the offset error in $\mathrm{q}$-axis current responses.

- The sliding mode control does not demonstrate a stand out performance compared to others. Generally, its response qualities are in between the on-off and predictive controls.
Table 5.

THD at 5 N.m of the load torque

\begin{tabular}{ll}
\hline Control & THD \\
\hline On-off & $23.87 \%$ \\
\hline Sliding mode & $23.35 \%$ \\
\hline Predictive & $21.90 \%$ \\
\hline Hybrid & $31.00 \%$ \\
\hline
\end{tabular}

- Looking at overall performances, results of this study show that the most appropriate type of control for the given PMSM is the predictive control.

\section{ACKNOWLEDGEMENT}

The authors are grateful to Kompetitif-LIPI activity and to all team members of electric machines and power electronics research group for all assistance that has been given.

\section{REFERENCES}

[1] I. Takahashi and T. Noguchi, "A new quickresponse and high-efficiency control strategy of an induction motor," IEEE Transactions on Industry Applications, vol. IA-22, pp. 820-827, Sept/Oct. 1986.

[2] C. French and P. Acarnley, "Direct torque control of permanent magnet drives," IEEE Transactions on Industry Applications, vol. 32, pp. 1080-1088, Sept/Oct 1996.

[3] L. Zhong, et al., "Analysis of direct torque control in permanent magnet synchronous motor drives," IEEE Transactions on Power Electronics, vol. 12, pp. 528-536, 1997.

[4] P. Pillay and R. Krishnan, "Modeling, simulation and analysis of permanentmagnet motor drives. Part I: the permanentmagnet synchronous motor drive," IEEE Transactions on Industry Applications, vol. 25, pp. 265-273, March/April 1989.

[5] A. Naik, et al., "Improved performance of adaptive hysteresis current controller based vector control of pmsm drive system," in Proceedings of the IEEE Student's Technology Symposium, 2011, pp. 1-8.

[6] H. M. Soliman and S. M. E. Hakim, "Improvement the current control methods for three phase voltage source inverter to drive the permanent magnet synchronous motor," International Journal of Engineering and Advanced Technology (IJEAT), vol. 2, pp. 53-61, October 2012.

[7] M. Novak, et al., "Application of sinusoidal phase current control for synchronous drive," in IEEE International Symposium on Industrial Electronics, 2006, pp. 2260-2265. 
[8] B. Zigmund, et al., "Experimental evaluation of pi tuning techniques for field oriented control of permanent magnet synchronous motors," Advances in Electrical and Electronic Engineering, pp. 114-119, 2012.

[9] K. Takahashi, et al., "High-performance inverter based on shaft acceleration torque for ac drives," IEEE Transactions on Industrial Electronics, vol. 60, pp. 66-77, January 2013.

[10] L. Harnefors and H. P. Nee, "Model-based current control of ac machines using the internal model control method," IEEE Transactions on Industry Applications, vol. 34, pp. 133-141, January/February 1998.

[11] T. S. Hu and C. J. Yeh, "Hardware implementation of the current control using the internal model method in the Electric Power Steering application," in IEEE Vehicle Power and Propulsion Conference, 2009, pp. 66-70.

[12] T. Miyajima, et al., "Synthesis and analysis of time-optimal current trajectory based on final-state control for ipmsm," in The 10th IEEE International Conference on Power Electronics and Drive Systems, Kitakyushu, Japan, 2013, pp. 433-438.

[13] P. Degobert, et al., "High performance control of the permanent magnet synchronous motor using self-tuning resonant controllers," in The Thirty-Eighth Southeastern Symposium System Theory, 2006, pp. 382-386.

[14] V. Repecho, et al., "Sensorless sliding mode control of pmsm drives using a high frequency injection algorithm," Przeglad Electrotechniczny (Electrical Review), vol. 88, pp. 16-20, 2012.

[15] B. Bossoufi, et al., "FPGAs in industrial current control for pmsm," International Journal of Emerging Technology and Advanced Engineering, vol. 2, pp. 131-142, February 2012.

[16] M. Curkovic, et al., "Fpga-based predictive sliding mode controller of a three-phase inverter," IEEE Transactions on Industrial Electronics, vol. 60, pp. 637-644, February 2013.

[17] J. W. Sun, et al., "A novel discrete-time predictive current control for pmsm," in ICCAS2005, 2005, pp. 1-6.

[18] P. Wipasuramonton, et al., "Predictive current control with current-error correction for $\mathrm{pm}$ brushless ac drives," IEEE Transactions on Industry Applications, vol. 42, pp. 1071-1079, July/August. 2006.

[19] F. Morel, et al., "A comparative study of predictive current control schemes for a permanent magnet synchronous machine drive," IEEE Transactions on Industrial Electronics, vol. 56, pp. 2715-2728, July 2009.

[20] S. Mariethoz, et al., "High-bandwidth explicit model predictive control of electrical drives," IEEE Transactions on Industry Applications, vol. 48, pp. 19801992, November/ December 2012.

[21] C. S. Lim, et al., "Model predictive control of a two-motor drive with five-leg inverter supply," IEEE Transactions on Industrial Electronics, vol. 60, pp. 54-65, January 2013.

[22] S. Chai, et al., "A cascade MPC control structure for a pmsm with speed ripple minimization," IEEE Transactions on Industrial Electronics, vol. 60, pp. 29782987, Augustus 2013.

[23] X. Lin-Shi, et al., "Implementation of hybrid control for motor drives," IEEE Transactions on Industrial Electronics, vol. 54, pp. 1946-1952, August. 2007.

[24] J.-W. Jung, et al., "Fuzzy PI-type current controllers for permanent magnet synchronous motors," in IET Electric Power Applications, 2011, pp. 143-152.

[25] A. V. Sant, et al., "Permanent magnet synchronous motor drive using hybrid pi speed controller with inherent and noninherent switching functions," IEEE Transactions on Magnetics, vol. 47, pp. 4088-4091, October 2011.

[26] J. Rodriguez, et al., "State of the art of finite control set model predictive control in power electronics," IEEE Transactions on Industrial Informatics, vol. 9, pp. 10031014, May 2013.

[27] A. Muqorobin and P. Irasari, "Analisis respon motor magnet permanent pada saat pengukuran parameter elektrik," Telaah, vol. 31, pp. 123-131, November 2013.

[28] M. P. Kazmierkowski, et al., Control in Power Electronics Selected Problem. San Diego: Elsevier Science, 2002.

[29] K. Ogata, Modern Control Engineering. New Jersey: Prentice hall, 2002. 